\title{
Relação das Contagens e Registros de Goiás - 1748
}

\section{Transcrição Paleográfica}

A riqueza aurífera das minas de Goiás resultou no esforço administrativo da coroa portuguesa para o controle da nova região de fluxo disperso de ocupação demográfica, resultando na proibição da abertura de novas estradas, na proibição do tráfego de rios, no desestímulo da agricultura e da pecuária e, acima de tudo, na fiscalização e aplicação de pesados tributos à atividade mineradora. Somente a mineração era permitida e estimulada pela coroa, mas sempre sujeita, como verificou Alencastre, "à capitação e censo, à venalidade dos empregados de registros e contagens, à falsificação na própria casa de fundição, ao quinto [...]" (ALENCASTRE, 1979, p. 18).

O controle, a arrecadação e a vigilância trouxeram as casas de fundição e o contrabando, pois este é decorrente daquele. Os excessos, permitidos pelos poderes conferidos aos administradores reinóis, amparavam-se na certeza da impunidade, que "nem o cipoal de leis, alvarás, cartas régias e provisões, nem os sequestros, devassas de registros, prêmios prometidos aos delatores e comissões aos soldados puderam pôr freio [...]" (PALACIN, 1979, p. 49). Vastos territórios, somente a diminuição e o controle sobre os acessos sugeria ao Estado uma possibilidade de controle sobre o processo produtivo e a aplicação dos impostos. Um vasto aparato legal, algum policiamento e a constante vigilância resultaram em relatórios, cartas e esclarecimentos sobre uma região sob constante tensão.

As proibições sobre as vias de acesso a Goiás foram declaradas logo nos primeiros anos da colonização mineradora. Em 1734, o tropeiro José da Costa Diogo foi penalizado com o confisco de sua mercadoria por ter trafegado de Minas Gerais para Goiás num momento em que o caminho se encontrava fechado por decreto (ROCHA JUNIOR; VIEIRA JÚNIOR; CARDOSO, 2006). Somente o caminho iniciado pelas bandeiras paulistas, ligando Goiás a São Paulo e Rio de Janeiro, permanecia aberto. Os acessos ao Pará e ao Maranhão, pelo Tocantins, os caminhos ao Piauí e à Bahia, e o percurso que dava acesso a Minas Gerais nas proximidades do rio São Francisco, ficavam interditados.

No interior, porém, o território goiano continuou se expandindo em vilas, estradas e fazendas, construindo uma teia, distinta das outras formas de ocupação do território brasileiro, com grandes distâncias entre os povoados e muitas estradas vicinais que tornavam as fazendas um fator importante no processo da ocupação portuguesa. Restou à coroa o controle fiscal das passagens principais através dos registros e das contagens, os postos estabelecidos nas saídas das minas e nos portos para fiscalizar a cobrança dos impostos e combater o contrabando. "O sistema de registros 'das entradas' foi implantado em Minas Gerais a partir de 1716; em Goiás, os primeiros foram instalados em 1732; em São Paulo, a partir de 1721, nas minas do Paranapanema” (RECEITA FEDERAL, 2011).

Deusdedith Alves Rocha Junior é historiador, professor e coordenador do curso de História do UniCEUB. Endereços eletrônicos: deusdedith. junior@uniceub.br; darochajr@hotmail.com.

Havia cinco tipos de registros. Os Registros do Ouro, que fiscalizavam o transporte do minério e cobravam o quinto; os Registros de Entradas, 
explorado por contratadores; os Registros dos "Meios Direitos da Casa Doada", que cobravam impostos sobre animais; os Registros da Demarcação Diamantina, que combatiam o contrabando de diamantes e faziam a cobrança das "entradas"; e as Contagens, que cobravam tributos sobre animais em trânsito (RECEITA FEDERAL, 2011). Localizados em pontos de circulação regular, os caminhos clandestinos eram vigiados pela repressão, canalizando o tráfego para as áreas controladas.

O pessoal dos registros se compunha de um Administrador (representante do Contratador), um Fiel (representante da Fazenda Real), um Contador e dois ou quatro soldados. Os prédios consistiam na "casa do registro", nas residências do fiel e do administrador, no quartel dos soldados, num rancho para os tropeiros contribuintes e num curral para os animais. A estrada era fechada por um portão com cadeado. O equipamento era mínimo: livros contábeis, cofre, balança com pesos, medidas para volumes, armas e utensílios domésticos (RECEITA FEDERAL, 2011).

Os registros e contagens foram montados e desmontados ao longo do período colonial, durante a monarquia brasileira e nos primeiros anos do século XX. Há, portanto, uma longa relação de registros que existiram por tempos variados. Em Goiás, a sua relação é imprecisa. Há muitos relatórios e outros documentos que dão conta deles e, em uma relação posterior a 1748, são destacados treze registros que, em comparação com os registros de Goiás descritos pelo site da Receita Federal, evidenciam a complexidade da construção das relações desses registros. Trata-se do documento número 0395, recolhido no Arquivo Histórico Ultramarino, nas caixas de Goiás.

A Receita Federal destacou os seguintes registros: Bandeirinha, Boa Vista, Traíras, Arrependidos, Insua, Lagoa Feia, Olhos d’Água, Salinas, Santa Maria, Santa Rita, Santo Antônio da Manga, São Bartolomeu, São Bernardo, São Domingos, São João das Duas Barras, São Marcos, Taguatinga, Caminho de Cuiabá, Desemboque, Duro, Rio das Éguas, Rio das Velhas e Tocantins. No entanto, na relação de 1748 somente três das acima citadas aparecem (São Bernardo, Rio das Velhas e Tocantins). Somam-se a estas, porém, mais dez registros: Três Barras, Pé da Serra, Minas de Santa Luzia, Taboatinga ou Boqueirão, Cavalcante, Ribeira do Paranã, Carmo, Chapada, São Félix e Natividade.

O documento que apresentamos faz parte do acervo do Arquivo Histórico Ultramarino, digitalizado e disponibilizado ao público brasileiro há mais de dez anos, que contém uma rica diversidade de documentos administrativos que foram recolhidos pelo Conselho Ultramarino, a Secretaria de Estado da Marinha e Ultramar, o Desembargo do Paço, a Casa da Índia e a Mesa da Consciência e Ordens, formando uma grande coleção da história colonial portuguesa.

O documento não possui uma assinatura e um autor conhecido, tendo sido identificado como posterior ao ano de 1748. Seus detalhes, porém são bastante esclarecedores quanto ao comércio, aos percursos e às distâncias no território goiano do período.

O documento encontra-se em bom estado para a leitura e é composto por duas cartas com caligrafias diferentes, uma remetendo ao conteúdo da outra. As poucas abreviaturas contidas não se constituíram dificuldades para a transcrição, que se baseou nas Normas Técnicas para a Transcrição e Edição de Documentos Manuscritos, do Arquivo Nacional, sendo, porém, desprezadas a quebra e a numeração de linhas, buscando tornar mais agradável a leitura. Pela mesma razão, as referências numéricas contidas ao lado do texto foram suprimidas, sem prejuízo do entendimento do conteúdo. O acervo consultado é referente à Capitania de Goiás e sua referência se encontra no Catálogo de verbetes dos manuscritos avulsos da capitania de Goiás existentes no Arquivo Histórico Ultramarino (TELES, 2001).

\section{Transcrição paleográfica}

395 [post. 1748] RELAÇÃO das contagens ou registros que tem o contrato das entradas nos continentes [da capitania de Goiás] e suas circunferências, com a distância que há entre eles e Vila Boa. AHU-Mato Grosso, cx.39, doc 51. AHU_ACL_CU_008, Cx. 5, D. 395

[fl 01]

Relaçaõ das Contagens, ou Registos que tem o Contrato das Entradas nos Continentes desta Capitania e suas Circunferencias, e das distancias que há desta Villa de huns a outros, e aos Arrayais da Comarca.

Desta Villa ao Registro Situado no Rio das Velhas, caminho para Povoado, Saõ cento e vinte Legoas. Por este Registo entra todo o Cómercio que vem da Cidade do Rio de Janeiro, para estas Minas, e se passavam nelle no Com tracto do Trienio preterito, quinhentas e oitenta Guias. 
Desta Villa ao Registo das Tres Barras, que fica no Caminho que vay para as Minas do Paracatú, e para o Sertaõ, Saõ cincoenta e duas Legoas. Por este Registo entra o Cómercio de Fazendas, e Escravos, que da Cidade da Bahia vem para esta Villa, para as Minas da Meya Ponte, e ainda para as de Pillar, e Crixaz: por elle entram taõbem os Gados, Cavalgaduras, Carnes Secas que vem do Sertaõ para esta Villa e para as ditas Minas, e taõbem algú genero de negocio do mesmo Sertaõ, como hé o Sal chamado vulgarmente da Terra, e alguns Couros de veado, e peixe dos Rios do mesmo Sertaõ: Nelle Se passaram nos tres annos do Contracto preterito, duzentos, quarenta, e Sete Guias.

Desta Villa ao Registo do Pé da Serra, que fica no Caminho que vem do Sertaõ para as Minas de de Pillar, e Crixaz, Saõ cincoenta e duas Legoas. Por elle entra a mayor parte do Cómercio, que vem da Bahia e do Sertaõ para as Minas do Pillar, e Crixaz na mesma forma que passa pelo antecedente das Tres Barras: Nelle se passaram em dous annos pertencentes ao Contracto do Triennio preterito, Sessenta e nove Guias.

Desta Villa ao Registo das Minas de Santa Luzia, que fica Situado dentro do mesmo Arrayal, Saõ Sessenta e quatro Legoas. Nelle Se conta o negocio, que na forma dos antecedentes, vem para estas Minas da Bahia, e Sertaõ: Nelle Se passáram, no Segundo anno, ao depois que as ditas Minas Se descobriram, oitenta e cinco Guias.

Desta Villa ao Arrayal de Sạo José das Minas de Tocantins, Saõ Settenta e duas Legoas: dahi ao Registo de Sẫ Bernardo Saõ onze Legoas, que vem a fazer oitenta e trez. Por este Registo emtra todo o Cómercio que vem / como pelos antecedentes / da Cidade da Bahia, e Sertaõ para as ditas Minas: Nelle Se passáram, nos tres annos do Contracto preterito, cento, quarenta e oito Guias.

Das Minas de Tocantins ao Registo, Situado na beira do Rio Tocantins, Saõ treze Legoas.

Por este Registo naõ passa mais genero de negocio algú, do que alguns Gados, Carne Secca, e algú Sabaõ da Terra, alguás cavalgaduras, ainda que muito poucas, que todos estes effeitos vem do Sertaõ das Terras Novas, que fica dentro do Destricto das Minas, e do Registo da Taboatinga, ou Boqueiraõ para dentro: Nelle Se passáram nos trez annos do Contracto preterito, Settenta e cinco Guias.
Deste Registo ao do Cavalcante, que fica Situado dentro do Arrayal das mesmas Minas Saõ vinte e trez Legoas. Nelle Se contam os mesmos effeitos, que no antecedente, que vem naõ Só do Sertaõ das Terras Novas, mas taõbem do da Ribeira do Paranã, que fica dentro do Districto das Minas: Nelle Se passáram em hú anno dos do Contracto preterito Sessenta e oito Guias.

Do Registo do Rio Tocantins ao do Sạ̃ Felix das Minas de Carlos Marinho, que fica Situado dentro do mesmo Arrayal, Saõ desessete Legoas. Neste Registo naõ se contam mais effeitos do que o Gado, Carnes Seccas, e algu Sabaõ, que entra do Sertaõ das Terras Novas, e Ribeira da Palma, e de Tocantins: Nelle Se passáram em hú dos annos do Contracto preterito, vinte e trez Guias.

Deste Registo do Arrayal do Carmo das mesmas Minas de Saõ Felix de Carlos Marinho, a donde taõbem Se acha outro Registo, em que Só Se contam os effeitos, que no antecedente, Saõ duas Legoas: Nelle Se passáram em hú dos annos do Contracto preterito, quinze Guias.

Deste Arrayal ao da Chapada das mesmas Minas, a donde Se acha outro Registo, em que Se contam os mesmos effeitos, que nos dous antecedentes, Saõ cinco Legoas: Nelle Se passaram em hú dos annos do Contracto preterito, trinta e seis Guias.

Do Arrayal das minas de São Felix ao das Minas das Arrayas, a donde há Registo, em que Se contam os mesmos effeitos, que nos trez antecedentes, Saõ quarenta Legoas: Neste Registo Se passáram em hú dos annos do Contracto preterito, cento, quarenta e nove Guias.

Das Minas de Sạo Felix ás da Natividade, a donde Se acha hú Registo, em que se contam os mesmos effeitos, que nos quatro antecedentes, Saõ Settenta Legoas: Nelle Se passáram em hú anno dos do Contracto preterito, cento, trinta e quatro Guias.

Deste Registo ao Descoberto do Carmo, das mesmas Minas da Natividade, em que há outro Registo, em que se contam os mesmos effeitos, que nos cinco antecedentes, Saõ trinta e Seis Legoas: Nelle Se passáram em hú dos annos do Contracto preterito desenove Guias.

Do Arrayal das Minas da Natividade, tornando a voltar para traz, pelo caminho, que vem para as Arrayas, e passado o Rio de Manoel Alves, tomando o Caminho chamado do Muleque, em direitura para a Contagem da Taboatinga, ou Boqueiraõ, Saõ cincoenta a [fl. 03] até 
Sessenta Legoas. Este Registo domina os Seguintes, por todos ficarem delle para dentro, a Saber: o do Cavalcante, o de Sa $\underline{0}$ Felix, o da Chapada, e das Arrayas; os dous da Natividade, e do Descuberto do Carmo das mesmas Minas, com advertencia que para o Cavalcante, e Arrayas podem entrar os que vierem da Bahia, Sem passar pelo Registo do Boqueiraõ, como já tem feito alguns, inda que poucos, tomando por huás Chapadas, que ficam nos Gerais do Sertaõ, do dito Registo do Boqueiraõ para fora.

Há mais o Registo do Campo aberto, que dista do Arrayal do Cavalcante vinte e quatro Legoas para a parte Leste, e desta Villa cento trinta e quatro.

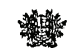

\section{ARQUIVO HISTÓRICO ULTRAMARINO}
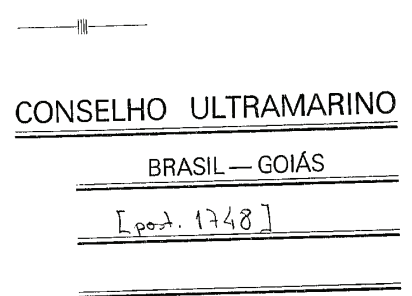

$\|^{0}$

395[post. 1748]
RELACÁ das contagens ou registros que term o contrato das entradas nos
continentes [da capitania de Goiás] e suas circunferéncias, com a distância que hà
entre eles e Vila Boa
AHU-Mato Grosso, cX. 39, doc. 51
AHU_ACL_CU_008, CX. 5, D. 395.

AHU_ACL_CU_008, CX, 5, D. 395.

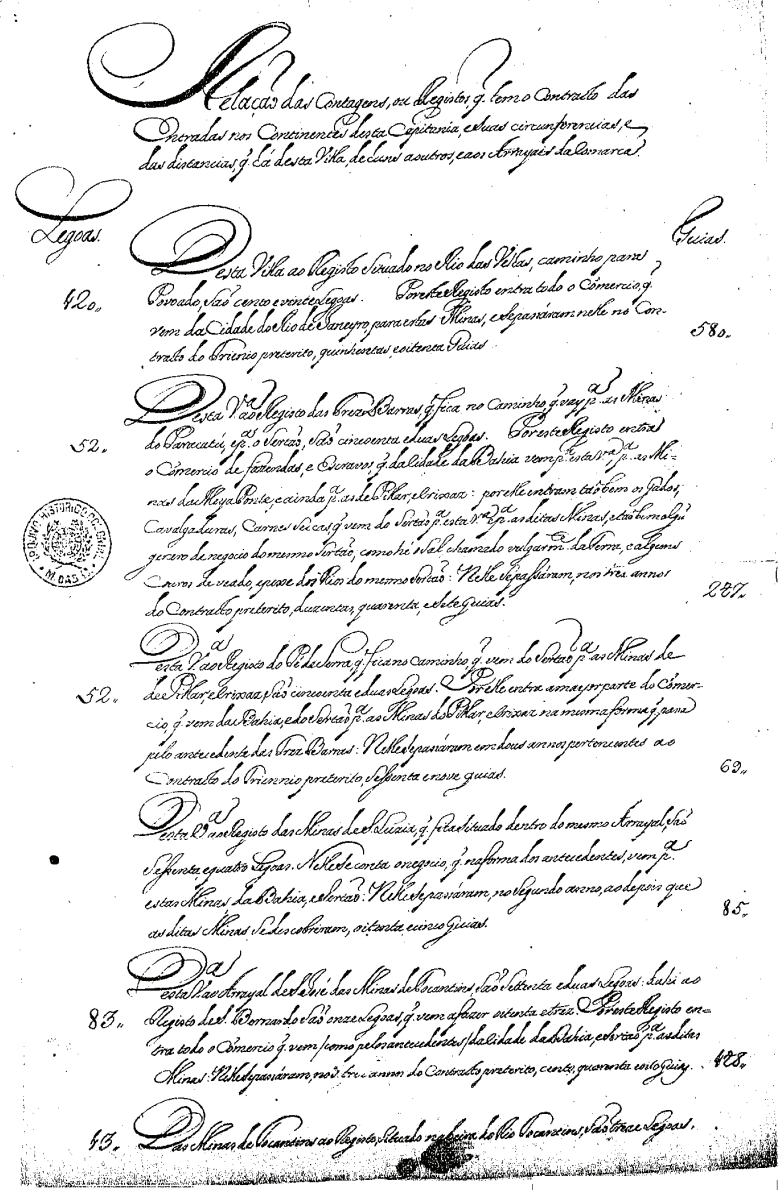

atg

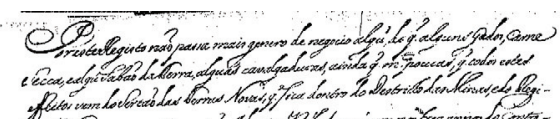

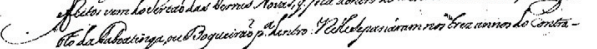

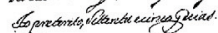

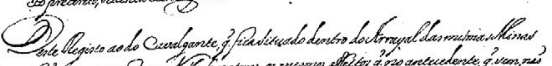

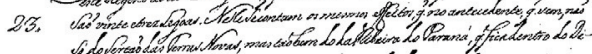

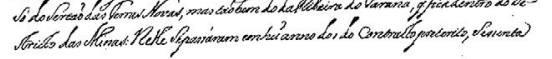

eocio gever.

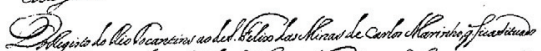

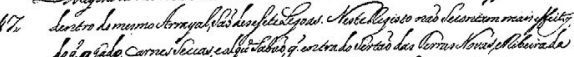

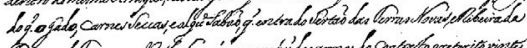

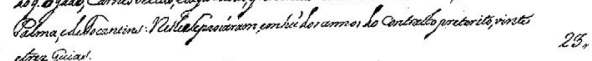

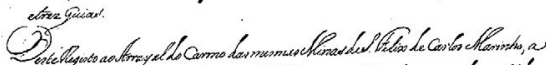

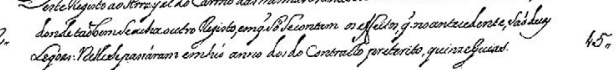

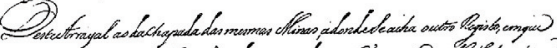

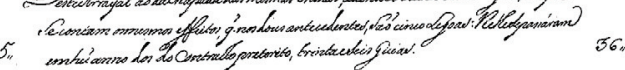

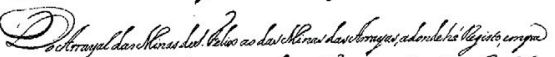

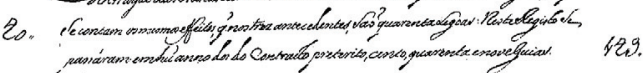

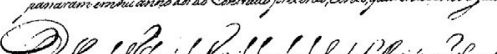

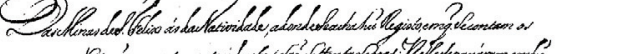

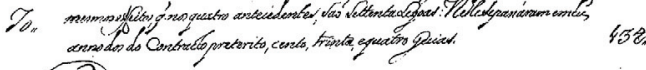

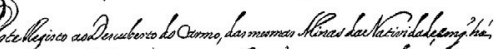

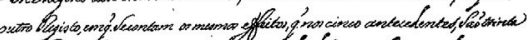

36.

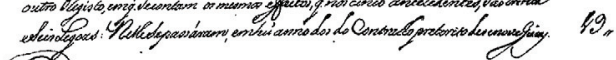

(2)

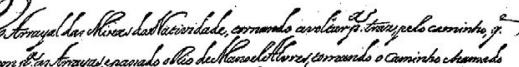

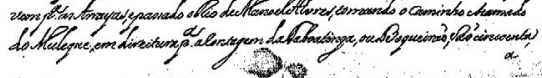




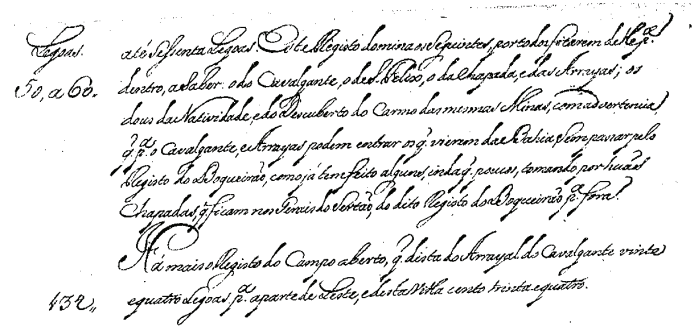

\section{Referências}

ALENCASTRE, José M. Pereira de. Anais da Província de Goiás - 1863. Brasília: Gráfica Ipiranga, 1979.

PALACIN, Luiz. Goiás 1722/1822: estrutura e conjuntura numa capitania de minas. Goiânia: Oriente, 1979.

RECEITA FEDERAL. Memória Receita Federal Registros, 2011. Disponível em: <http://www.receita. fazenda.gov.br/Memoria/administracao/reparticoes/ colonia/registros.asp>. Acesso em: 26 fev. 2011.

ROCHA JUNIOR, Deusdedith; VIEIRA JÚNIOR, Wilson; CARDOSO, Rafael Carvalho. Viagem pela estrada real dos Goyazes. Brasília: Paralelo 15, 2006.

TELES, José Mendonça (Org.). Catálogo de verbetes dos manuscritos avulsos da capitania de Goiás existentes no Arquivo Histórico Ultramarino, Lisboa-Portugal. Goiânia: Sociedade Goiana de Cultura, Institutos de Pesquisas e Estudos Históricos do Brasil-Central, 2001. 


\section{Para publicar na revista}

Universitas Humanas,

acesse $o$ endereço eletrônico www.publicacoesacademicas.uniceub.br. Observe as normas de publicação, para facilitar e agilizar o trabalho de edição. 